\title{
Hvor lang kan en nese bli?
}

\author{
Det var kanskje et dumt spørsmål, men få vet riktig svar: En nese kan aldri bli lengre enn \\ 11 tommer, for da er den en fot! I alle fall er nesen et organ som folk biter seg skikkelig \\ merke i. Det er ikke tilfeldig at mange folkelig ordtak og forestillinger knytter seg til kroppens \\ mest fremspringende organ. Her er to eksempler: \\ - Spelemannsfoten er alltid kåt, og fantenasen er alltid våt. \\ - Tre ting er låke å løyna: Kjærleik, hoste og ein raud nase.
}

Nesen er egentlig et nokså komplisert organ og har en sentral plass både i pusten og i varmereguleringen. Den bærer også preg av det livet vi har levd. Begrepet portvinsnese er et godt eksempel, men ved misbruk av sterkere drikkevarer kan nesen ikke bare bli rød, men også blå og lyse som et fyrtårn. Det hevdes også at nesens form blir påvirket av klimaet (1).

Ikke minst er nesen et organ for luktesansen. Hele 10000 ulike lukter klarer den å holde styr på, både gode og vonde. Og noen virker direkte inn på kjønnsdriften. Med vanlig luktesans klarer vi også å identifisere kjemiske stoffer i konsentrasjoner som ligger helt ned i grenseland for vanlige kjemiske analyser.

I perioder har nesens betydning som fysiologisk og sosialt organ vært altfor lite påaktet. Derfor var det velgjørende da professor Per Holck i 2001 presenterte en omfattende artikkel om medisinhistoriske aspekt ved nesen. Og få var vel mer kvalifiserte til å ta på seg denne oppgaven enn nettopp han. Ved siden av å ha arbeidet som professor i anatomi ved Universitetet i Oslo i mange år, har han et omfattende forfatterskap som inkluderer fagartikler, folkemedisin og medisinsk historie.
I denne artikkelen som vi nå trykker på ny, gir han viktige bidrag til å forstå nesens eiendommelige posisjon, knyttet til forfengelighet og utseende.Den plastiske og rekonstruktive kirurgien begynte for $\varnothing v r i g$ med nesen. Når han forteller med historiske eksempler hvor galt det kan gå når nesen ikke er i orden, må vi erkjenne det samme som trubaduren Ivar Medaas gjorde da han skrev sin populære vise:

Ver glad i den nasen du har!

\section{Ole Didrik Lærum}

ole.laerum@gades.uib.no

Ole Didrik Lærum (f. 1940) er professor (adj.) ved Københavns Universitet og professor emeritus ved Universitetet i Bergen.

\section{Litteratur}

1. Weiner JS. Nose shape and climate. Am J Phys Anthropol 1954; 12: 615-8

\section{Nesen i medisinhistorisk lys}

Holck P. Nesen i medisinhistorisk lys. Tidsskr Nor Lægeforen 2001; 121: 2019-22.

En av de egenskaper som skiller menneskene fra dyrene er forfengeligheten. Allerede steinaldermenneskene brukte pynt og smykker for å skape seg et så fordelaktig ytre som mulig, og denne menneskelige egenskap er så visst ikke blitt mindre fremtredende gjennom århundrene.

På samme måte som oppfatningen av hva som var pent og stygt har vekslet sterkt, både tidsmessig og geografisk, har også synet på vår fysiognomi variert atskillig, slik som motene. Neppe noen annen kroppsdel har i så måte hatt en slik betydning som vår nese, hvilket denne artikkelen gir en oversikt over.
Især er nasale defekter blitt oppfattet som særlig vansirende. I Italia foretok man allerede på 1500-tallet avanserte plastiske inngrep med stilket hudlapp og gradvis fjerning av hudsuturene. Den slags aktivitet ble naturlig nok bannlyst av kirken, slik at adelig beskyttelse av utøveren ofte var en nødvendighet.

De gamle romerne kalte nesen for «ansiktets pryd», og gjennom hele vår sivilisasjons historie har den vært som et speilbilde av eieren selv, både den sosiale posisjon og karakter til hans eller hennes stolthet eller fortvilelse. Både størrelsen og formen har på en underlig måte virket som et signal til omverdenen om vedkommendes egenskaper av så vel etisk som fysisk og psykisk art.

\section{Nese og ånd}

Den sveitsiske presten Johann Caspar Lavater (1741-1801) som på 1700-tallet utviklet sin underlige pseudovitenskap fysiognomikken, hvor individets åndelige karakter ble satt i relasjon til utseendet, uttalte om nesen at den var «hjernens speilbilde» og at det kunne gå 1000 vakre øyne på hver vakker nese (1). Han innrømmet riktignok at enkelte åndsmennesker hadde vært forsynt med stygge neser, og nevner i den forbindelse filosofen Sokrates og maleren Tizian som eksempler, men stort 


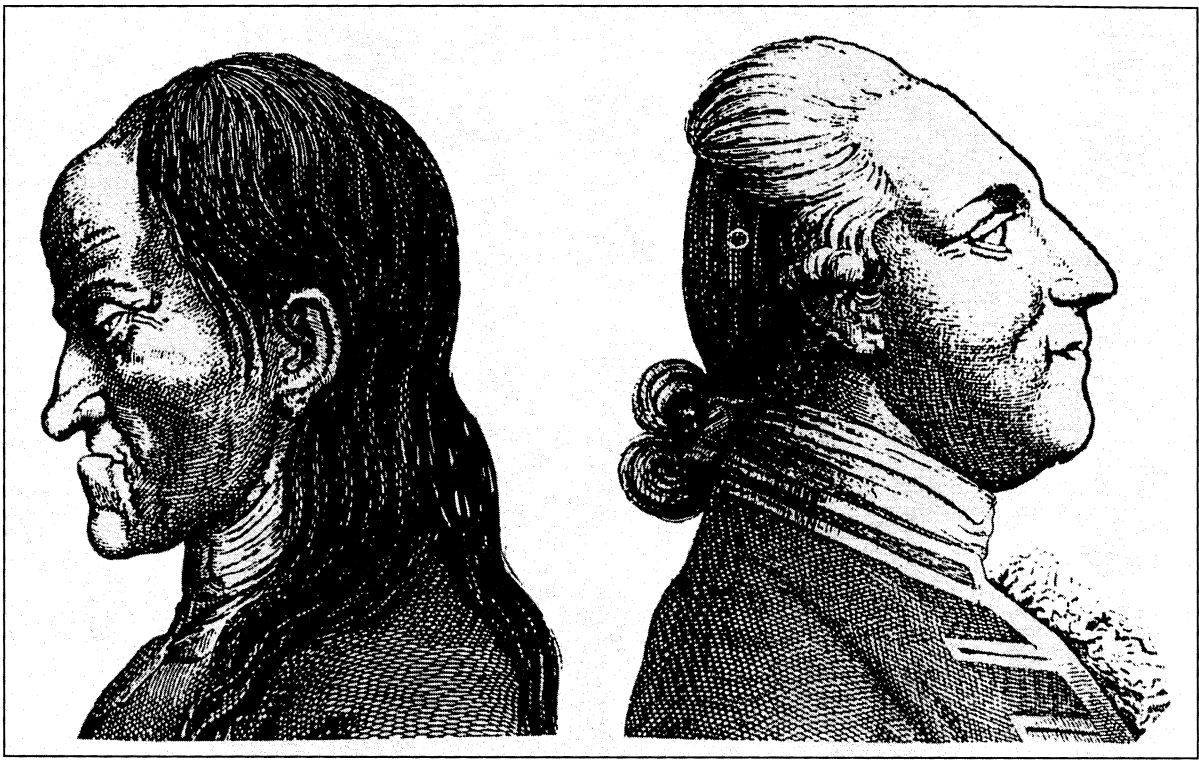

Figur 1 Det «dårlige» og det «gode» menneske - med tilhørende neser. Stikk fra Lavaters Physiognomische Fragmente (1)

sett mener han at en stygg nese er ensbetydende med et uedelt menneske (fig 1).

I henhold til Lavater skulle en vakker nese være som følger: Lengden skal være lik pannens høyde (innehaverens eventuelle hårprakt nevnes ikke i den forbindelse), ved neseroten må det være en liten fordypning, forfra må neseryggen være bred og parallell, kanskje litt bredere på midten, og nesetippen må verken være hard og spiss eller stor og kjøttfull, i profil må den nederste horisontale del ikke utgjøre mer enn en tredel av hele lengden, nesen må for øvrig

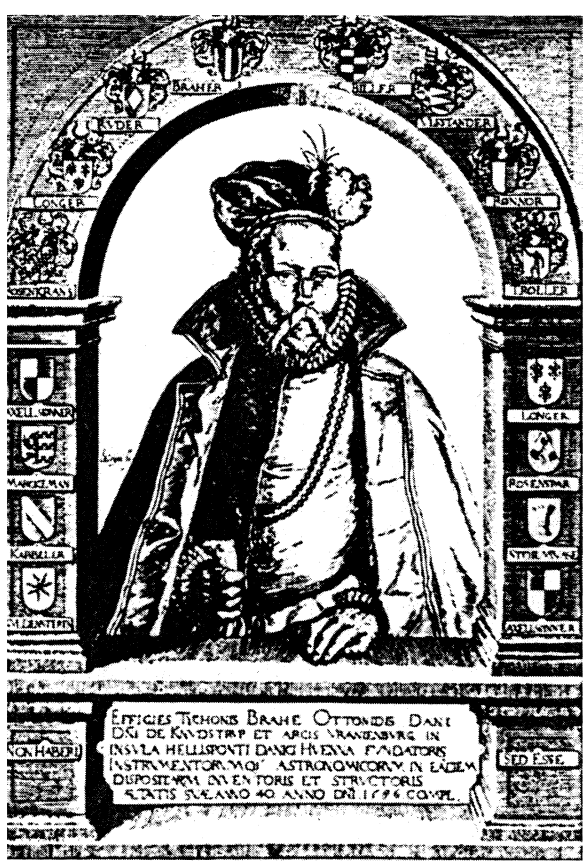

Figur 2 Tycho Brahe(1546-1601). Etterkobberstikk av Jacob de Gheyn, 1586 gå direkte over i øyebrynene, og der skal den ikke ha større bredde enn en halv tomme. Og endelig må neseborene foran være litt spisse, baktil mer runde, og de må være akkurat passe store. Små nesebor oppfattes nemlig som et tegn på fryktsomhet. Derimot er nesevinger som beveger seg når man puster - stadig ifølge Lavater - et ugjendrivelig bevis på holdninger som kan utarte til vellyst

En idealnese blir derfor, som en konklusjon på denne belæring, «mer verd enn et kongerike» (1)!

\section{Nesen som botsmiddel}

Men hensynet til nesen og verdsettelsen av dens utseende er ganske visst mye eldre. I kong Valdemars sjællandske lov fra begynnelsen av 1200-tallet, forløperen for Christian Vs lov fra 1683, regnes nesen som ett av mannens tre hovedorganer som det skulle svares full bot for. Selv tap av øynene, hendene og føttene ble bare taksert til halv bot.

Siden nesen stod så høyt i kurs i eldre tid, forstår man bedre hvilken katastrofe det må ha vært å leve med vansirende sykdommer, slik som f.eks. spedalskhet, som jo nettopp angriper bl.a. neseregionen. Middelalderens barbariske avstraffelsesmetoder konsentrerte seg derfor ikke sjelden om nesen. Det kan være en levning etter dette når vi i våre eventyr får vite at man for å bli kvitt byttinger skulle knipe dem i nesen med en gloende ildtang (2)

Under utgravningen av den middelalderske Peterskirken i Tønsberg ble det for noen år siden funnet en hodeskalle som bar tydelige tegn på å ha fått nesen skåret av $(3,4)$. Rent umiddelbart kunne man tenke seg at dette var en mann som i kampens hete hadde fătt sin legemspryd ødelagt, men pussig nok viste det seg at skallen var av en kvinne! Hennes gravsted i periferien av kirkegårdens nordside plasserer henne med stor sannsynlighet lavt nede på den sosiale rangstigen. Her lå nemlig de fattige, de utstøtte og de straffede i middelaldersamfunnet, i henhold til kirkerettslovene. Og man kommer Gulatingslovens ord i hu i den forbindelse, for den sier om avstraffelse om tyver: «Om en trell eller løysingskvinne stjeler, skal hun første gang få det ene øret avskåret, ved annen gangs tyveri tar man det andre øret. Men blir hun grepet i tyveri for tredje gang, skal hun få nesen avskåret. Da heter hun stuve og nuve og kan stjele så mye hun vil» (5)! Tanken bak denne salomoniske lovteksten var vel at den som ikke passet seg og sitt gods for neseløse personer, kunne takke seg selv om han ble bestjålet.

\section{Tycho Brahe}

Likevel har vi nok av historier om at man kunne miste nesen under andre og mer uheldige omstendigheter. Velkjent i så måte er den berømte danske astronom, lege og fysiker Tycho Brahe (1546-1601). Han ble oppfostret hos sin onkel, som hadde en meget høy stjerne hos kong Frederik II. Da onkelen døde i 1565, arvet den 19-årige Tycho ikke bare hans formue, men også den kongelige gunst, som var god å ha i en tidsalder da man ikke ustraffet syslet med astronomi.

Tycho Brahe var i sin samtid like kjent for sin store viten som for sitt ufordragelige vesen. Han er beskrevet som en hoven og selvgod kverulant som elsket å komme i diskusjon og klammeri med andre (6). Og det var da heller ingen mangel på slike anledninger i den tiden. Under et studieopphold i Rostock ved juletider 1566 kom han i krangel med en adelig landsmann, Manderup Parsbjerg, etter at vinen hadde gått de to herrene til hodet.

De avtalte å møtes utenfor for å gjøre opp, hvilket betydde duell med dragne kårder, som den gang var en naturlig del av utstyret. Om Tycho Brahe var den fulleste eller den dårligste fekteren av de to, skal være usagt. Iallfall endte duellen med at han lå blødende igjen på marken, med nesen halvt avskåret.

Etter dette ble de to kamphanene faktisk ganske gode venner - like barn leker som kjent best. Men Tycho Brahe måtte resten av livet gå med sin skavank - en svær defekt over neseryggen, som han forsøkte å skjule så godt han kunne. Han fikk først laget en voksprotese, men den ville ikke sitte ordentlig fast. I stedet gikk han med en metallplate av kobber, malt hudfarget, som hver morgen ble festet med lim på restene av neseryggen (7). Den er for øvrig til stede på samtlige portretter vi kjenner av ham 
(fig 2), men manglet da Tycho Brahes balsamerte legeme ble gravd opp i 1901, 300 år etter hans død, i Praha. Kanskje har en eller annen graver ment at han hadde mer nytte av nesen enn den opprinnelige eieren.

Men neser kunne også være en direkte årsak til duell. Vi kjenner historien om den franske forfatter og slåsskjempe Cyrano de Bergerac (1619-55), som skal ha utkjempet mer enn 1000 dueller på grunn av nedsettende kommentarer om det enorme snyteskaftet han etter sigende var utstyrt med.

\section{Sara trenese}

Fra vår hjemlige litteratur kjenner vi en annen, mer tragisk skikkelse enn de to foregående. Jeg tenker da på Camilla Colletts (1813-95) fortelling om «Sara trenese» eller Sara Sandmark, som var hennes virkelige navn. I memoarboken I de lange Ncetter fra 1862 (8) beretter hun om denne kvinnen som i fattige kår oppdrog sin store barneflokk til dannelse, ærbarhet - og kultur! Sara Sandmark var nemlig et makeløst oppkomme av eventyr, både norske og utenlandske - datteren Lisbeth Maria ble således P.C. Asbjørnsens (1812-85) kilde til flere av de fortellinger han nedskrev fra Eidsvollstraktene. I så måte gikk kunnskapene i arv. Camilla Collett forteller at Sara om kvelden fortalte eventyr for sine barn for at de skulle glemme at de ikke hadde noe å spise, og hun sier om datteren at «hun maa ofte have sultet, thi hun kunde mange Eventyr» (8).

Sara var i sin ungdom den vakreste piken i bygden, og hun ble såkalt godt forlovet. Kort før hun skulle reise ned til København for å gifte seg med sin tilkommende, ble hun - mot sin vilje - invitert til et bryllup hvor det ble danset. Camilla Collett forteller (8): «Foran dem dansede Hans Østgaarden; han havde svoret at han skulde træffe Krogen i Taget med sin Fod ... En vild Huien og et rasende Kast med Legemet viser, at det er hans Alvor, en jernskoet Hæl blinker mod Loftet - Støv, Forvirring - da Løitnanten vender sig for at gribe sin Dame, ligger hun besvimet paa Jorden. Hun bæres bort, Dansen fortsættes, som om intet var paaferde. Hvad var det ogsaa i Grunden? - Stakkels Sara! - en Fremtid var spildt ... En Fremtid, en Kjæreste ... en Næse.»

Den vansirede piken fikk ringen i retur fra sin forlovede. En gammel treskjærer $i$ bygden laget $i$ stedet to treneser til henne, en simpel til hverdags og en malt og polert til søndagsbruk.

\section{En skrækkelig Operation}

Memoarforfatterinnen Conradine Dunker (1780-1866) forteller i sin bok Gamle Dage (utgitt posthumt i 1871) en historie som gir et pussig innblikk i både sykdomsteorier og operasjonsmetoder, for ikke å snakke om underlige familiære forhold ved slutten av det 18. århundre. Hun skriver (9):

«En meget gammel og meget riig Frue i Drammen havde indsat til sin Arving en ung Mand, mig synes, han heed Bugge. Fruen laae syg, og Arvingens Pligt var nu at pleie hende, og dette gjorde han trolig og vaagede over hende baade Nat og Dag. For at holde sig vaagen om Natten havde han vænnet sig til at bruge Snuustobak, men da Lugten heraf faldt den Syge til Besvær, saa brugte han istedet derfor pulveriseret Sukker. Dette troede man var Aarsag i, at han fik en Polyp i Næsen, der snart tog saaledes Overhaand, at den maatte defigurere hans Ansigt. Fruen døde, Rigdommen var hans, men han vovede ikke at komme for øinene af den unge Dame, han var forelsket i, med sit defigurerede Ansigt. Forgjeves anmodede han Lægerne om at befrie ham fra Polypen; de erklærede, at det var ugjørlig. Thulstrup alene sagde, at denne Operation vel var mulig, men forbunden med saadanne Lidelser og Vanskeligheder, at han raadede ham derfra; heller ikke vilde han paatage sig den. Men Bugge vedblev saa længe at overhænge ham, til han føiede ham. Det var en skrækkelig Operation, og Lidelsen var stor for begge Parter. Fire stærke Karle holdt Bugge, og i Convultioner brækkede han flere Stole istykker ... » (Magnus Andreas Thulstrup (1769-1844) ble var første professor i «Chirurgi og Fødselsvidenskab». Om ham sier Conradine Dunker at han hadde reddet manges liv, men ikke alltid deres lemmer. Vi skal huske at dette var lenge for noen anestesi eller narkose kom i bruk!)

Men historien endte godt. Polyppen ble fjernet og mannen ektet sin donna. Til takk mottok dr. Thulstrup (fig 3) 1000 riksdaler samt en diamantring.

\section{Tidlig rhinoplastikk}

Forsøk på korreksjon av manglende eller deformerte neser er blitt gjort på et meget tidlig tidspunkt. Dette har riktignok skjedd $i$ andre deler av verden, hvor det i flere tusen år var vanlig å la nesene bøte for eiernes tyvaktighet. Fra India kjenner vi f.eks. de eldgamle Ayurveda-skriftenes detaljerte instruksjoner om hvordan man skulle rekonstruere bløtdelene etter totallesjon av den ytre nesen. Man tok et blad fra en slyngplante og klippet det ut til en modell av den manglende legemsdel. Bladet ble lagt utover kinnet, og en hudlapp av samme form og størrelse ble skåret til, dreid inn og festet ti1 de oppfriskede sårrendene på den tidligere nesens plass. Til slutt ble to små sivrør anbrakt der hvor neseborene skulle være, og det hele ble så dekket til med knuste plantedeler og forbundet med bomull fuktet med sesamfrøolje. Når såret var grodd, ble stilken overskåret og nesen tilpasset sin endelige form (10).

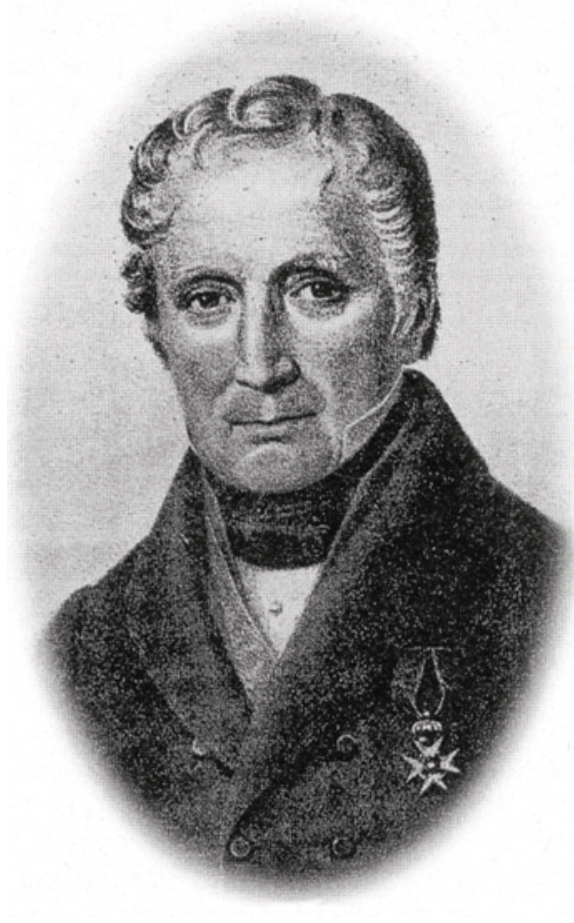

Figur 3 Magnus Andreas Thulstrup (1769-1844). Litografi etter maleri av Johan Görbitz

Disse operasjonene ble tradisjonelt utført av folk fra pottemakernes kaste, altså sosialt sett lavtstående personer. Inngrepet hadde gjennom århundrene et visst lyssky skjær over seg, og teknikken ble overlevert fra lærer til elev i muntlig form. Først på 1700tallet fikk man i Europa mer kjennskap til dette, bl.a. gjennom ryktene om at en gurkhakonge skulle ha befalt at en hel bys innbyggere skulle få nesene avskåret som straff for den motstand de hadde vist under hans beleiring. Byen har siden hett Naskatapoor, som rett og slett betyr «De avskårne nesers by» (10)!

Vi kan nok tro at det har vært et visst behov for slike neserekonstruksjoner, for datidens indiske ektemenn kunne etter sigende straffe sine koner ved å skjære av dem nesen. Om skikken har vært alminnelig utbredt skal være usagt, det var nemlig ikke anledning til å skille seg eller forstøte den annen part uten at nesen satt der den skulle.

I den vesterlandske medisinen ble rekonstruksjon av nesen omtalt som en kjent, men lite anbefalelsesverdig prosess av de klassiske forfattere (11). Men gjennom araberne, som hadde forbindelser både østover og mot Europa, må det i løpet av senmiddelalderen ha blitt brakt kunnskap om den orientalske operasjonsteknikken. Alt på 1400-tallet har vi vitnesbyrd om at rekonstruktive neseoperasjoner ble utført i den vestlige verden, bl.a. i Catania på det arabiskdominerte Sicilia av en viss Branca og hans sønn Antonio, hvor teknikken lenge 


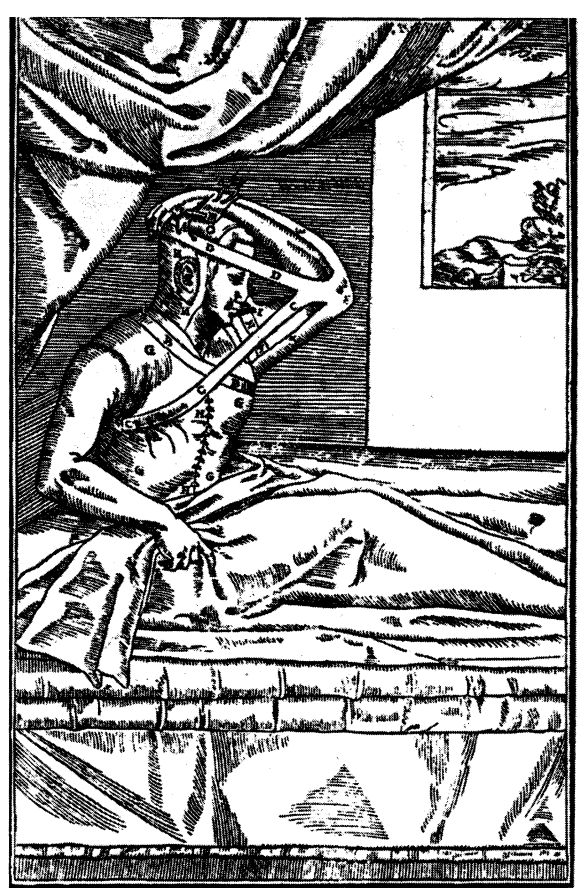

Figur 4 Hudlappen er sydd fast til nesen og armen immobilisert ved hjelp av et sinnrikt bandasjesystem. Tresnitt fra Gaspare Tagliacozzis bok De curtorum chirurgia, Venezia, 1597

ble bevart som en familiehemmelighet. Branca senior brukte hud fra pannen eller kinnet, mens sønnen anvendte hud fra overarmen til å rekonstruere defekter på så vel nese som lepper og ører, for dermed å unngå skjemmende arr i ansiktet (12).

Gjennom hele 1500-tallet finner vi tilsvarende operasjonsbeskrivelser, bl.a. av berømte anatomer som Gabriele Falloppio (1523-62) eller Andreas Vesalius (1514-64). Ingen av dem forsøkte seg vel på inngrepet $\mathrm{i}$ praksis $(12,13)$, og det har åpenbart eksistert atskillige misforståelser, bl.a. trodde man at nesen ble rekonstruert av armens muskulatur, og ikke av huden. Den franske kirurgen Ambroise Paré (1510-90) beskriver attpåtil hvordan vevet til den nye nesen skulle tas fra bicepsmuskelen, hvor det ble laget et hull som det defekte organet ble presset ned i, for så etter de «magiske» 40 dager å bli frigjort og endelig utformet. Han sier likevel at han tviler på om en slik nese vil ta seg særlig godt ut, verken i form eller farge (10).

\section{Tagliacozzis metode}

I 1597 ble en av de merkeligste bøker i medisinhistorisk sammenheng utgitt i Venezia. Den hadde tittelen De curtorum chirurgia per incisione ..., (Om lemlestelses-kirurgi ved tilskjæring...) og var skrevet av legen og kirurgen Gaspare Tagliacozzi (1546-99). Han var født i Bologna som sønn av en rik silkevever, og kunne derfor uten større økonomisk bekymring begynne sine studier ved byens berømte universitet. Han må ha vært en begavelse utenom det vanlige, for straks etter at han tok sin doktorgrad i 1570 ble han utnevnt til professor i kirurgi $(10,13)$.

Tagliacozzi synes snart å ha fått ry som motelege, og ble som sådan knyttet til det kunst- og vitenskapselskende hoffet til hertugene av Mantua, hvor også berømtheter som Donatello, Leonardo da Vinci, Claudio Monteverdi o.a. hadde fått økonomisk støtte. Vi må også tro at hertugen personlig, Vinzenzo Gonzaga (d. 1627), har holdt sin beskyttende hånd over Tagliacozzi, hvilket nok var en fordel, ikke minst overfor Kirken, som så med største uvilje på alle som praktiserte kirurgi.

Det er derfor ikke underlig at boken er dedisert til nettopp hertugen av Mantua. Det som imidlertid gjør den så spesiell, er at de plastikkirurgiske rekonstruksjonene beskrives av en mann som selv har utført dem. Behov for slik behandling har ikke bare ligget $\mathrm{i}$ tidens omgang med skarpe våpen, også den nye «epidemi» av syfilis gjorde dette nødvendig for mange. Hvordan Tagliacozzi har kommet til sine kunnskaper, vet vi ikke, og vi trenger vel heller ikke å gruble over det. I stedet skal vi se litt nærmere på boken og dens innhold.

Etter de tradisjonelle hyllingsdikt og dedikasjoner - de utgjør ikke mindre enn 21 sider - gir Tagliacozzi en oversikt over fagets historie og teori. Ansiktets anatomi og den betydning dette har for personligheten gjennomgås på historisk og filosofisk grunnlag. I den siste delen av boken blir operasjonen beskrevet i deta1j (10).

Pasienten må forberedes skikkelig med medikamenter som avhenger av hans temperament. Lider han av veneriske sykdommer, påbegynnes behandlingen flere måneder før selve inngrepet. Tagliacozzi legger stor vekt på lett kost og lite vin. Alle slags belastninger må unngås, men mosjon er bra, særlig om morgenen. Om kvelden bør pasienten gå sulten til sengs.

Operasjonen skal foregå i den riktige tid på året, helst om våren, da det ikke bør være for fuktig. Rommet hvor operasjonen skal finne sted, bør være lyst og luftig. Til stede er kun operatøren og to assistenter - ingen tilskuere, i motsetning til hva som ellers var vanlig i medisinske kretser på den tid. Sengen skal stå midt i rommet, tilgjengelig fra alle sider og forsynt med puter av ull, ikke dun, som blir for bløtt. En halv time før inngrepet vaskes skulderen og overarmen med eddikvann, og kirurgen ser etter at alle instrumenter er på plass og at knivene er skarpe. Alt er hans eget ansvar, ikke assistentenes! Pasienten plasseres på sengekanten, slik at lyset faller riktig. Den ene assistenten støtter pasienten, den andre hjelper kirurgen. Alle instruksjoner blir gitt med et nikk, da tale vil forstyrre pasienten. Lappens plassering på overarmen avmerkes med blekk, og det legges to parallelle snitt som det trekkes et stykke lerret gjennom, slik at det dannes en hudbro. Over den legges det en forbinding, og pasienten blir bedt om å holde seg i ro de neste dagene (fig 4). Streng diett og ingen vin!

14 dager senere løsnes lappens ene ende, og etter ytterligere et par uker utføres operasjonens annen del, som Tagliacozzi beskriver slik (10):

«Aftenen før operasjonen barberes hår og skjegg bort. Flass og lus fjernes. Neste formiddag anbringes pasienten med ansiktet mot vinduet i en høyrygget stol uten armlene. Tilstede er - foruten kirurgen og hans to assistenter - også en skredder som skal ta mål og tilpasse støttebandasjene som i den kommende tid skal fiksere pasientens arm til hans hode. Instrumentene skal rekkes kirurgen slik at pasienten ikke kan se dem. Nesearret oppfriskes og det klippes til en papirmodell av den nye nesen som hudlappen skjæres til etter. Suturene anbringes og pasienten føres til sin seng, hvor suturene strammes og knyttes, og bandasjen anbringes. Dette er en handling som kirurgen under ingen omstendighet må overlate til sine assistenter, hvor dyktige de enn måtte være! Den følgende tid settes pasienten på en meget streng diet; all føde må være flytende og gis med skje, da tygging må unngås. For å slippe arr etter suturene blir de første trådene fjernet etter 4 dager, resten 3 dager senere. Etter et par uker overskjæres lappen, og den nye nesen tilpasses og fastsyes. På neseborenes plass anbringes små rør og over neseryggen legges en metallform, helst av sølv eller gull, foret med silke som må skiftes daglig. Formen blir holdt på plass av silkebånd og bæres i to år etter operasjonen ... »

Naturlig nok ble denne boken med sine tresnitt uhyre kostbar og bare trykt i få eksemplarer. Den ble imidlertid revet bort, og allerede samme år var første piratutgave på markedet. Boken utkom for siste gang så sent som i 1831, da med en dedikasjon til samtidens mest berømte kirurg Johann Friedrich Dieffenbach (1792-1847). Den var da fremdeles like aktuell og «moderne» (13).

\section{Ettertiden}

Tagliacozzi døde bare to år etter utgivelsen av sitt verk, og mange så nok dette som en velfortjent straff fra de høyere makter. Han ble imidlertid bisatt med pomp og prakt i klosterkirken San Giovanni Battista i hjembyen Bologna. Der fikk han ligge i fred i bare ett år, for nonnene i klosteret hadde på mystisk vis begynt å høre stemmer som fordømte Gaspares sjel til evig fortapelse. Graven ble derfor åpnet og legemet tatt ut og begravet på nytt utenfor kirken - ingen vet lenger hvor. 
Det var heller ingen som våget å gjenoppta de vanskelige operasjonene etter Tagliacozzis død. De fikk etter hvert et overnaturlig skjær over seg, og hadde det ikke vært for boken, ville hans viten ha gått $\mathrm{i}$ graven med ham.

Ettertiden tenkte seg at huden, for å spare fornemme folk for operasjonens lidelser, kunne tas fra et annet menneske, f.eks. en slave eller tjener. Men samtidig trodde man at det ville oppstå et slags symbiotisk forhold mellom donor og resipient, slik at dersom donor gikk hen og døde, sa ville transplantatet som tilhørte ham også dø. Man latterliggjorde Tagliacozzis verk, slik som f.eks. den engelske dikteren Samuel Butler i sitt epos Hudibras (1663-78), hvor han, for å få frem det komiske i situasjonen, lot donorstedet flytte til bakenden.

Først ved begynnelsen av 1800-tallet tok engelske og tyske kirurger opp igjen indisk og italiensk operasjonsteknikk. Først ute var Joseph Carpue (1764-1846), som i tidsskriftet The Gentleman's Magazine for 1794 presenterte en artikkel om et slikt inngrep som han hadde hørt om fra India. I 1814 utførte han den første rhinoplastikk i moderne tid (13). To år senere fulgte tyskeren Carl Ferdinand von Graefe (1787-1840).

Først i vår egen tid har Tagliacozzis fremragende metode fullt ut blitt forstått. Etter mer enn 400 år skulle vel tiden være moden for det.

\section{Per Holck}

per.holck@basalmed.uio.no

Anatomisk institutt

Universitetet i Oslo

Postboks 1105 Blindern

0317 Oslo

Basert på foredrag ved Buskerud legeforenings seminar på Geilo 27.1. 2001

\section{Litteratur}

1. Lavater JC. Physiognomische Fragmente zur Beforderung der Menschenkenntnis und Menschenliebe. Leipzig: 1775-78.

2. Ekebergkongen. Asbjørnsen og Moes samlede eventyr. Bd. 3. Oslo: Gyldendal, 1965.

3. Holck P. To catch a thief. A find from a medieval churchyard. Chieti: Monographic Publication 1. Journal of Palaeopathology, 1989: 121-4.

4. Holck P. Skjelettmaterialet fra Tønsberg. En antropologisk rapport. Anatomiske skrifter nr. 2 Oslo: Anatomisk institutt, Universitetet i Oslo. 1989 .

5. Gunnes E. Rikssamling og kristning. Norges historie. Bd. 2. Oslo: Cappelen, 1976.

6. Clemedson C-J. Något om Tycho Brahe och hans medicinska verksamhet. Sydsvenska medicinhistoriska sällskapets årsskrift 1972: 38-59.

7. Lee DC. Tycho Brahe and his sixteenth century nasal prothesis. Plast Reconstr Surg 1972; 50: $332-7$

8. Collett C. I de lange Nætter. Samlede Verker, Bd 1 . Kristiania/København: Gyldendal, 1912.

9. Dunker C. Gamle Dage. Erindringer og Tidsbilleder. København: Gyldendal, 1871

10. Thomsen M. Plastikkirurgiens ældre historie. Årbog 1973. Odense: Dansk medicinsk-historisk Selskab, 1973: 136-57.
11. Kollesch J, Nickel D. Antike Heilkunst. Ausgewählte Texte aus den medizinischen Schriften der Griechen und Romer. Stuttgart: Reclam, 1994.

12. Toellner R. Illustrierte Geschichte der Medizin, Bd. 5. Vaduz: Andreas Verlag, 1992

13. Hirsch A. Biographisches Lexikon der hervorragenden Aerzte aller Zeiten und Völker. Wien/ Leipzig: Urban \& Schwarzenberg, 1884.

Holck P.

A brief history of nasal fashion.

Tidsskr Nor Laegeforen 2001; 121 : 2019-22.

Vanity, it seems, is one of the qualities that separate us from other species; indeed, we may be said to possess it in excess. Decorating body and apparel with all kinds of objects in order to look attractive goes a long way back in time; even Stone Age man knew how to make himself look smart.

This very human trait has not abated over the millennia, but the perception of what looks good has changed a great deal, just like fashion, and no part of the human body has probably been of such significance in this respect as the nose. This article presents a brief review of nasal fashion. 